\title{
HUBUNGAN SANITASI KAPAL DENGAN KEBERADAAN TIKUS PADA KAPAL YANG BERLABUH DI PELABUHAN TRISAKTI BANJARMASIN
}

\author{
Norhayati, Yohanes Joko, M. Irfa'i \\ Poltekkes Kemenkes Banjarmasin Jurusan Kesehatan Lingkungan \\ Jl. H. Mistar Cokrokusumo No.1A Banjarbaru Kalimantan Selatan 70714 \\ E-mail: norhayati2528@gmail.com
}

\begin{abstract}
The Correlation Between Ships Sanitation And The Signs of The Rats Presence On The Ships That Rest In Trisakti Port Banjarmasin 2017. In accordance with the International Health Regulation (IHR) 2005 and the Regulation of the Minister of Health of the Republic of Indonesia No. 356 of 2008, the Port Health Office is responsible for the port area be rat-free infestation. Ports and ships must be free from the rats presence but data in the ships are find the presence of rats, so it must be fumigation. This study aimed to know the correlation between ships sanitation and the rats presence on ships that rest in Trisakti Port Banjarmasin 2017. This study type was observation in analytic form with cross sectional approach. This samples size were motor boats, tug boat ships, motor vessels and motor tankers, so their total were 20 ships. The instrument used ship sanitation inspection form and rats inspection form. Data analysis used the Fisher Exact Test. Based on the results of statistical test with Fisher Exact Test obtained p-value $=0.017$. Thus, $p$-value count $<p$ value alpha [0.05], so $\mathrm{H}_{0}$ was rejected. That means it was correlation between ships sanitation and the signs of the rats presence on ships that rest in the Trisaksi Port Banjarmasin 2017.
\end{abstract}

Keywords: Ships sanitation; signs of rats; rats on ships.

\begin{abstract}
Abstrak: Hubungan Sanitasi Kapal Dengan Tanda-Tanda Keberadaan Tikus Pada Kapal Yang Berlabuh Di Pelabuhan Trisakti Banjarmasin. Sesuai dengan ketetapan International Health Regulation (IHR) tahun 2005 dan Peraturan Menteri Kesehatan Republik Indonesia no.356 tahun 2008. Kantor Kesehatan Pelabuhan bertanggung jawab agar daerah pelabuhan bebas dari infestasi tikus. Pelabuhan dan kapal harus bebas dari keberadaan tikus, tetapi dari data ditemukan kapal dengan keberadaan tikus, sehingga harus dilakukan fumigasi. Tujuan dari penelitian ini adalah mengetahui hubungan antara sanitasi kapal dengan keberadaan tikus pada kapal yang bersandar di pelabuhanTrisakti Banjarmasin Tahun 2017. Jenis penelitian ini adalah observasi dalam bentuk analitik dengan pendekatan cross sectional. Sampel penelitian ini berupa kapal motor, kapal tug boat, motor vessel dan motor tanker yang berjumlah 20 kapal. Instrumen yang digunakan adalah formulir pemeriksaan sanitasi kapal dan formulir pemeriksaan tikus di kapal. Analisis data menggunakan uji Fisher Exact Test. Berdasarkan hasil uji statistic menggunakan uji Fisher Exact Test di peroleh nilai p-value $=0,017$. Dengan demikian pvalue hitung < p-value alpha $(0,05)$, sehingga $\mathrm{H}_{0}$ ditolak. Berarti ada hubungan antara sanitasi kapal dengan tanda-tanda keberadaan tikus pada kapal yang bersandar di PelabuhanTrisakti Banjarmasin tahun 2017.
\end{abstract}

Kata Kunci: Sanitasi kapal; Tanda-tanda keberadaan tikus; Tikus di kapal.

\section{PENDAHULUAN}

Kapal adalah semua alat angkut yang dapat berlayar dan harus bebas dari faktor risiko lingkungan sehingga tidak menjadi tempat perkembang biakan vektor penyakit dan tidak menularkan penyakit di dalam kapal [1]. Di dalam International Health Regulation 2005
[IHR], World Health Organization (WHO) merekomendasikan kepada negara peserta untuk melakukan tindakan terhadap bagasi, kargo, petikemas, alat angkut, barang-barang, paket pos atau jenazah manusia untuk menghilangkan infeksi atau kontaminasi termasuk vektor 
dan reservoir, tanpa pembatasan perjalanan dan perdagangan [2].

Mengingat Undang-undang No.1

Tahun 1962 tentang karantina laut menjelaskan bahwa penyakit pes merupakan salah satu penyakit karantina yang masih berlaku secara internasional, maka kondisi sanitasi kapal merupakan faktor yang sangat penting. Upaya sanitasi kapal yaitu penyehatan, pengamanan, dan pengendalian terhadap faktor risiko lingkungan untuk memutus mata rantai penularan penyakit atau kontaminasi [3]. Hal ini bertujuan untuk penerbitan sertifikat sanitasi guna memperoleh Surat Izin Kesehatan Berlayar [SIKB] [4].

Berdasarkan Depkes RI (2007), pemeriksaan tikus di kapal dilakukan dengan melihat tanda-tanda kehidupan tikus yaitu dropping (kotoran tikus), runways (jalan tikus), tracks (bekas tapak kaki), gnawing (bekas gigitan) dan tikus hidup/mati [5]. Hasil review beberapa penelitian, tikus yang ditemukan pada kapal berbendera Indonesia lebih banyak meskipun sanitasi pada kapal sudah baik [6]. Hal tersebut dikaitkan dengan rendahnya sanitasi yang mengindikasikan minimnya penyediaan air bersih dan sanitasi dek kapal, serta masih ditemukannya vektor atau rodent dalam kapal meskipun dalam jumlah yang relatif kecil [7].

Berdasarkan data yang diperoleh dari Kantor Kesehatan Pelabuhan (KKP) Kelas II Banjarmasin bahwa sejak Januari sampai Desember 2016 sebanyak 1299 buah kapal yang bersandar di daerah pelabuhan Trisakti Banjarmasin masih terdapat 2 kapal yang memiliki sanitasi kapal buruk dan harus dilakukan tindakan penyehatan kapal dengan cara fumigasi kapal. Keadaan sanitasi kapal yang kurang memenuhi persyaratan kesehatan dapat menjadi sumber keberadaan tikus dikapal.

KKP sebagai Unit Pelaksana Teknis di lingkungan Kementerian Kesehatan mempunyai tugas melaksanakan pencegahan masuk dan keluarnya penyakit potensial wabah. Sebagai leading sector dalam mewujudkan kondisi Pelabuhan Banjarmasin Sehat, mengharuskan KKP Kelas II Banjarmasin untuk berperan lebih optimal dalam menginformasikan segala kegiatan yang telah dilaksanakan terutama yang berkaitan dengan pencapaian tujuan pembangunan kesehatan di wilayah pelabuhan. [8]. Salah satu cara pengendalian tersebut adalah dengan pengawasan sanitasi di kapal-kapal yang berlabuh di wilayah kerja Kantor Kesehatan Pelabuhan Kelas II Banjarmasin.

Berdasarkan uraian tersebut maka perlu dilakukan penelitianmengenai "Hubungan Sanitasi Kapal dengan TandaTanda Keberadaan Tikus pada Kapal yang Berlabuh di Pelabuhan Trisakti Banjarmasin Tahun 2017".

\section{BAHAN DAN CARA PENELITIAN}

Populasi dalam penelitian ini adalah kapal yang datang berlabuh dan melakukan pemeriksaan sanitasi kapal di wilayah kerja Pelabuhan Trisakti pada tanggal 05 April-29 Mei 2017. Sampel dalam penelitian ini ditentukan dengan metode accidental sampling, yaitu sebagian kapal yang dating berlabuh untuk melakukan pemeriksaan sanitasi kapal sebanyak 20 buah kapal.

Penelitian ini menggunakan desain penelitian potong lintang (cross sectional), menilai sanitasi kapal dan data mengenai variable terikat, tanda-tanda keberadaan tikus pada kapal yang dikumpulkan dalam waktu yang bersamaaan dan secara langsung. Analisis univariat dilakukan terhadap tiap variabel dari hasil penelitian dengan menggunakan distribusi frekuensi untuk mengetahui gambaran terhadap variabel yang diteliti. Analisis bivariat dilakukan untuk mengetahui hubungan antara variabel bebas dan terikat, menganalisis hubungan antara kondisi sanitasi kapal dengan tanda-tanda keberadaan tikus di kapal yang berlabuh di pelabuhan Trisakti Banjarmasin digunakan uji Fisher Exact Test, dengan bantuan program komputer SPSS. Uji Fisher Exact Test merupakan uji yang digunakan untuk menganalisis jumlah sampel yang relatif kecil dengan skala data nominal atau ordinal [9]. 
HASIL PENELITIAN DAN PEMBAHASAN

1. Hasil Pemeriksaan Sanitasi Kapal
Hasil pemeriksaan sanitasi kapal dapat dilihat dari Tabel 1 dan 2 :

Tabel 1. Distribusi Hasil Pemeriksaan Sanitasi Kapal Di Pelabuhan Trisakti Banjarmasin Tahun 2017

\begin{tabular}{ccc}
\hline Sanitasi Kapal & Jumlah & Persentase \\
\hline Memenuhi Syarat & 11 & $55 \%$ \\
Tidak Memenuhi Syarat & 9 & $45 \%$ \\
Total & 20 & $100 \%$ \\
\hline
\end{tabular}

Berdasarkan Tabel 1 diketahui dari 20 kapal, kapal yang memenuhi syarat sebanyak 11 kapal [55\%] dan kapal yang tidak memenuhi syarat sebanyak 9 kapal [45\%]. Pemeriksaan sanitasi kapal dengan cara penilaian menggunakan formulir observasi dengan menilai tiaptiap ruangan kapal yang sudah ditetapkan didalam formulir observasi.

Tabel 2. Distribusi Hasil Pemeriksaan Sanitasi Kapal Dilihat dari Masing-Masing Ruangan Di Pelabuhan Trisakti Banjarmasin Tahun 2017

\begin{tabular}{llccccc}
\hline No & $\begin{array}{c}\text { Ruang yang } \\
\text { diamati }\end{array}$ & $\begin{array}{c}\text { Memenuhi } \\
\text { Syarat }\end{array}$ & $\%$ & $\begin{array}{c}\text { Hasil } \\
\text { Memenuhi } \\
\text { Syarat }\end{array}$ & $\%$ & Jumlah \\
\hline 1 & Dapur & 49 & 49 & 51 & 51 & 100 \\
2 & Ruang rakit makan & 68 & 68 & 32 & 32 & 100 \\
3 & Gudang & 52 & 52 & 48 & 48 & 100 \\
4 & Kamar mandi & 75 & 94 & 5 & 6 & 80 \\
5 & Kamar ruangan & 66 & 66 & 34 & 34 & 100 \\
& Total & 310 & 65 & 170 & 35 & 480 \\
\hline
\end{tabular}

Berdasarkan Tabel 2 diketahui bahwa dari 20 kapal persentase yang paling banyak tidak memenuhi syarat berada pada ruang dapur yaitu sekitar 51\%. Sedangkan jika dilihat dari total keseluruhan penilaian item-item sanitasi kapal $65 \%$ sudah memenuhi syarat dan
35 persen belum memenuhi syarat. Adapun item-item yang dinilai dapat diketahui sebagai berikut.

a. Sanitasi Dapur Kapal

Hasil pemeriksaan sanitasi dapur dapat dilihat pada tabel 3:

Tabel 3. Hasil Pemeriksaan Sanitasi Kapal Bagian Dapur Kapal Di Pelabuhan Trisakti Banjarmasin Tahun 2017

\begin{tabular}{|c|c|c|c|c|c|c|}
\hline \multirow[b]{2}{*}{ No } & \multirow[b]{2}{*}{ Sanitasi Dapur } & \multicolumn{4}{|c|}{ Hasil } & \multirow[b]{2}{*}{ Jumlah } \\
\hline & & $\begin{array}{l}\text { Memenuhi } \\
\text { Syarat }\end{array}$ & $\%$ & $\begin{array}{c}\text { Tidak } \\
\text { Memenuhi } \\
\text { Syarat }\end{array}$ & $\%$ & \\
\hline 1 & Bersih & 12 & 60 & 8 & 40 & 20 \\
\hline 2 & Ada tempat sampah tertutup & 6 & 30 & 14 & 70 & 20 \\
\hline 3 & Alat-alat bersih & 15 & 75 & 5 & 25 & 20 \\
\hline 4 & Pencahayaan & 8 & 40 & 12 & 60 & 20 \\
\hline \multirow[t]{3}{*}{5} & $\begin{array}{l}\text { Tidak ada tanda kehidupan } \\
\text { vektor }\end{array}$ & 8 & 40 & 12 & 60 & 20 \\
\hline & Total & 49 & & 51 & & \\
\hline & [\%] & 49 & & 51 & & \\
\hline
\end{tabular}


Dari Tabel 3 dapat diketahui bahwa dari 20 kapal dengan 5 item persyaratan yang dinilai dalam formulir observasi $49 \%$ sanitasi dapur memenuhi syarat dan $51 \%$ sanitasi dapur tidak memenuhi syarat.

Pada pemeriksaan dapur kapal menunjukkan kapal yang memiliki dapur bersih sebanyak 12 kapal [60\%] sedangkan tidak memenuhi syarat 8 kapal [40\%]. Kapal yang memiliki fasilitas tempat sampah yang tertutup sebanyak 6 kapal [30\%] sedangkan tidak memenuhi syarat sebanyak 14 kapal [70\%]. Kapal yang memiliki fasilitas peralatan dapur yang bersih sebanyak 15 kapal [75\%] sedangkan tidak memenuhi syarat sebanyak 5 kapal [25\%]. Kapal yang memiliki fasilitas pencahayaan yang baik sebanyak 8 kapal [40\%] sedangkan tidak memenuhi syarat sebanyak 12 kapal [60\%]. Dan kapal yang tidak ada ditemukan tanda keberadaan vektor didapur sehingga memenuhi syarat sebanyak 8 kapal [40\%] sedangkan tidak memenuhi syarat sebanyak 12 kapal [60\%].

b. Sanitasi Ruang Rakit Makan Kapal Hasil sanitasi ruang makan kapal dapat dilihat tabel 4:

Tabel 4. Hasil Pemeriksaan Sanitasi Kapal Bagian Ruang Rakit Makan Kapal Di Pelabuhan Trisakti BanjarmasinTahun 2017

\begin{tabular}{|c|c|c|c|c|c|c|}
\hline \multirow[b]{2}{*}{ No } & \multirow[b]{2}{*}{ Sanitasi Ruang Rakit Makan } & \multicolumn{4}{|c|}{ Hasil } & \multirow[b]{2}{*}{ Jumlah } \\
\hline & & $\begin{array}{l}\text { Memenuhi } \\
\text { Syarat }\end{array}$ & $\%$ & $\begin{array}{c}\text { Tidak } \\
\text { Memenuhi } \\
\text { Syarat }\end{array}$ & $\%$ & \\
\hline 1 & Bersih & 16 & 80 & 4 & 20 & 20 \\
\hline 2 & $\begin{array}{l}\text { Ada tempat sampah } \\
\text { tertutup }\end{array}$ & 14 & 70 & 6 & 30 & 20 \\
\hline 3 & Alat-alat bersih & 17 & 85 & 3 & 15 & 20 \\
\hline 4 & Pencahayaan & 11 & 55 & 9 & 45 & 20 \\
\hline 5 & $\begin{array}{l}\text { Tidak ada tanda kehidupan } \\
\text { vektor }\end{array}$ & 10 & 50 & 10 & 50 & 20 \\
\hline & Total & 68 & & 32 & & \\
\hline & {$[\%]$} & 68 & & 32 & & \\
\hline
\end{tabular}

Dari Tabel 4 dapat diketahui bahwa dari 20 kapal dengan 5 item persyaratan yang dinilai dalam formulir observasi $68 \%$ sanitasi ruang rakit makan memenuhi syarat dan $32 \%$ sanitasi ruang rakit makan tidak memenuhi syarat.

c. Sanitasi Gudang Kapal

Hasil sanitasi gudang kapal dapat dilihat tabel 5:

Tabel 5. Hasil Pemeriksaan Sanitasi Kapal Bagian Gudang Kapal Di Pelabuhan Trisakti BanjarmasinTahun 2017

\begin{tabular}{|c|c|c|c|c|c|c|}
\hline \multirow[b]{2}{*}{ No } & \multirow[b]{2}{*}{ Sanitasi Gudang } & \multicolumn{4}{|c|}{ Hasil } & \multirow[b]{2}{*}{ Jumlah } \\
\hline & & $\begin{array}{l}\text { Memenuhi } \\
\text { Syarat }\end{array}$ & $\%$ & $\begin{array}{c}\text { Tidak } \\
\text { Memenuhi } \\
\text { Syarat }\end{array}$ & $\%$ & \\
\hline 1 & Bersih & 14 & 70 & 6 & 30 & 20 \\
\hline 2 & $\begin{array}{l}\text { Ada tempat sampah } \\
\text { tertutup }\end{array}$ & 13 & 65 & 7 & 35 & 20 \\
\hline 3 & Alat-alat bersih & 12 & 60 & 8 & 40 & 20 \\
\hline 4 & Pencahayaan & 2 & 10 & 18 & 90 & 20 \\
\hline 5 & $\begin{array}{l}\text { Tidak ada tanda kehidupan } \\
\text { vektor }\end{array}$ & 11 & 55 & 9 & 45 & 20 \\
\hline & Total & 52 & & 48 & & \\
\hline & {$[\%]$} & 52 & & 48 & & \\
\hline
\end{tabular}


Dari Tabel 5 dapat diketahui bahwa dari 20 kapal dengan 5 item persyaratan yang dinilai dalam formulir observasi $52 \%$ sanitasi gudang memenuhi syarat dan $48 \%$ sanitasi gudang tidak memenuhi syarat.
d. Sanitasi Kamar Mandi
Hasil sanitasi kamar mandi kapal dapat dilihat tabel 6:

Tabel 6. Hasil Pemeriksaan Sanitasi Kapal Bagian Kamar Mandi Kapal Di Pelabuhan Trisakti Banjarmasin Tahun 2017

\begin{tabular}{|c|c|c|c|c|c|c|}
\hline \multirow[b]{2}{*}{ No } & \multirow[b]{2}{*}{ Sanitasi Kamar Mandi } & \multicolumn{4}{|c|}{ Hasil } & \multirow[b]{2}{*}{ Jumlah } \\
\hline & & $\begin{array}{c}\text { Memenuhi } \\
\text { Syarat }\end{array}$ & $\%$ & $\begin{array}{c}\text { Tidak } \\
\text { Memenuhi } \\
\text { Syarat }\end{array}$ & $\%$ & \\
\hline 1 & Bersih & 18 & 90 & 2 & 10 & 20 \\
\hline 2 & Tidak berbau sengit & 18 & 90 & 2 & 10 & 20 \\
\hline 3 & Kran berfungsi baik & 20 & 100 & 0 & 0 & 20 \\
\hline 4 & $\begin{array}{l}\text { Tidak ada tanda kehidupan } \\
\text { vektor }\end{array}$ & 19 & 95 & 1 & 5 & 20 \\
\hline & Total & 75 & & 5 & & \\
\hline & {$[\%]$} & 94 & & 6 & & \\
\hline
\end{tabular}

Dari Tabel 6 dapat diketahui bahwa dari 20 kapal dengan 4 item persyaratan yang dinilai dalam formulir observasi $94 \%$ sanitasi kamar mandi memenuhi syarat dan $6 \%$ sanitasi kamar mandi tidak memenuhi syarat. e. Sanitasi Kamar Ruangan [Kelasi, Perwira, Penumpang, Geladak] Hasil sanitasi kamar ruangan kapal dapat dilihat tabel 7:

Tabel 7. Hasil Pemeriksaan Sanitasi Kapal Bagian Kamar Ruangan Kapal Di Pelabuhan Trisakti Banjarmasin Tahun 2017

\begin{tabular}{|c|c|c|c|c|c|c|}
\hline \multirow[b]{2}{*}{ No } & \multirow[b]{2}{*}{ Sanitasi Kamar Ruangan } & \multicolumn{4}{|c|}{ Hasil } & \multirow[b]{2}{*}{ Jumlah } \\
\hline & & $\begin{array}{l}\text { Memenuhi } \\
\text { Syarat }\end{array}$ & $\%$ & $\begin{array}{c}\text { Tidak } \\
\text { Memenuhi } \\
\text { Syarat }\end{array}$ & $\%$ & \\
\hline 1 & Bersih & 17 & 85 & 3 & 15 & 20 \\
\hline 2 & $\begin{array}{l}\text { Ada tempat sampah } \\
\text { tertutup }\end{array}$ & 8 & 40 & 12 & 60 & 20 \\
\hline 3 & Alat-alat bersih & 18 & 90 & 2 & 10 & 20 \\
\hline 4 & Pencahayaan & 7 & 35 & 13 & 65 & 20 \\
\hline 5 & $\begin{array}{l}\text { Tidak ada tanda } \\
\text { kehidupan vektor }\end{array}$ & 16 & 80 & 4 & 20 & 20 \\
\hline & Total & 66 & & 34 & & \\
\hline & {$[\%]$} & 66 & & 34 & & \\
\hline
\end{tabular}

Dari Tabel.7 dapat diketahui bahwa dari 20 kapal dengan 5 item persyaratan yang dinilai dalam formulir observasi $66 \%$ sanitasi kamar ruangan memenuhi syarat dan $34 \%$ sanitasi kamar ruangan tidak memenuhi syarat.

\section{Hasil Pemeriksaan Tanda} Keberadaan Tikus Di Kapal

Hasil pemeriksaan tanda keberadaan tikus dapat dilihat tabel 8 dan 9 : 
Tabel 8. Distribusi Hasil Pemeriksaan Tanda Keberadaan Tikus Di Kapal pada Pelabuhan Trisakti Banjarmasin Tahun 2017

\begin{tabular}{ccc}
\hline $\begin{array}{c}\text { Tanda keberadaan tikus di } \\
\text { kapal }\end{array}$ & Jumlah & Persentase \\
\hline Positif & 7 & $35 \%$ \\
Negatif & 13 & $65 \%$ \\
Total & 20 & $100 \%$ \\
\hline
\end{tabular}

Berdasarkan Tabel 8 diketahui dari 7 kapal yang positif ditemukan tanda keberadaan tikus, ada 3 kapal yang tanda keberadaan tikusnya ditemukan di ruangan yang berbeda yaitu 2 kapal ditemukan di ruang dapur dan gudang serta 1 kapal ditemukan diruang rakitmakan dan gudang.Sedangkan 4 kapal lainnya hanya ditemukan 1 tanda keberadaan tikus setiap kapalnya.
Pemeriksaan tanda keberadaan tikus ini dilaksanakan dengan panduan form observasi, apabila ditemukan 1 atau lebih dari 5 tanda keberadaan tikus, maka kapal tersebut dinyatakan positif [tidak memenuhi syarat]. Tanda yang paling banyak ditemukan dapat dilihat pada tabel dibawah ini:

Tabel 9. Distribusi Tanda Keberadaan Tikus yang sering ditemukan Di Kapal pada Di Pelabuhan Trisakti Banjarmasin Tahun 2017

\begin{tabular}{|c|c|c|c|c|c|c|c|}
\hline \multirow[b]{2}{*}{$\begin{array}{l}\text { Ruang yang } \\
\text { Diamati }\end{array}$} & \multicolumn{5}{|c|}{ Tanda yang Ditemukan } & \multirow[b]{2}{*}{ Jumlah } & \multirow[b]{2}{*}{ [\%] } \\
\hline & $\begin{array}{c}\text { Kotoran } \\
\text { Tikus }\end{array}$ & $\begin{array}{l}\text { Jalan } \\
\text { Tikus }\end{array}$ & $\begin{array}{c}\text { Bekas } \\
\text { Tapak Kaki }\end{array}$ & $\begin{array}{c}\text { Bekas } \\
\text { Gigitan }\end{array}$ & $\begin{array}{c}\text { Tikus } \\
\text { Hidup/Mati }\end{array}$ & & \\
\hline Dapur & 5 & - & - & - & - & 5 & 50 \\
\hline $\begin{array}{l}\text { Ruang rakit } \\
\text { makan }\end{array}$ & 1 & - & - & - & - & 1 & 10 \\
\hline Gudang & 3 & - & - & 1 & - & 4 & 40 \\
\hline Kamar mandi & - & - & - & - & - & 0 & 0 \\
\hline Ruang Kamar & - & - & - & - & - & 0 & 0 \\
\hline Total & 9 & 0 & 0 & 1 & 0 & 10 & 100 \\
\hline Persentase [\%] & 90 & 0 & 0 & 10 & 0 & 10 & 100 \\
\hline
\end{tabular}

Berdasarkan Tabel 9 dari 20 kapal dapat diketahui tanda-tanda keberadaan tikus yang paling sering ditemukan yaitu ditemukannya kotoran tikus pada dapur kapal sebanyak 5 kali [50\%]. Sedangkan tempat yang paling jarang ditemukan bahkan tidak pernah ditemukan yaitu dikamar mandi dan ruang kamar kapal [0\%]. Sedangkan tanda yang paling sering dijumpai dikapal juga kotoran tikus yaitu 9 kali [90\%] dan tanda gigitan tikus hanya 1 kali [10\%].

\section{Hubungan Sanitasi Kapal dengan Tanda-Tanda Keberadaan Tikus}

Hubungan sanitasi kapal dengan tanda-tanda keberadaan tikus dapat dilihat tabel 10: 
Tabel 10. Hubungan Sanitasi Kapal Dengan Tanda Keberadaan Tikus Di Kapal Pada Pelabuhan Trisakti BanjarmasinTahun 2017

\begin{tabular}{ccccccc}
\hline \multirow{2}{*}{ Sanitasi Kapal } & \multicolumn{3}{c}{ Tanda Keberadaan Tikus } & \multirow{2}{*}{ Jumlah } & \multirow{2}{*}{ P-Value } \\
\hline $\begin{array}{c}\text { Memenuhi } \\
\text { Syarat }\end{array}$ & 1 & 9 & 10 & 91 & 11 & \\
$\quad \begin{array}{c}\text { Tidak } \\
\text { Memenuhi }\end{array}$ & 6 & 67 & 3 & 33 & 9 & \\
$\quad \begin{array}{c}\text { Syarat } \\
\text { Total }\end{array}$ & 7 & & 13 & & 20 & \\
\hline
\end{tabular}

Berdasarkan hasil uji statistik, menggunakan uji alternatif yaitu uji Fisher Exact Test dan di peroleh nilai p-value $=$ 0,017 dengan demikian $\mathrm{p}$-value hitung < p-value $\alpha[0,05]$, sehingga $\mathrm{H}_{0}$ ditolak, yang berarti ada hubungan antara sanitasi kapal dengan tanda-tanda keberadaan tikus.

\section{KESIMPULAN DAN SARAN}

Berdasarkan hasil penelitian diketahui bahwa dari 20 kapal, kapal yang memenuhi syarat sebanyak 11 kapal [55\%] dan kapal yang tidak memenuhi syarat sebanyak 9 kapal [45\%], Diketahui bahwa dari 20 kapal, kapal yang ditemukan positif tanda keberadaan tikus sehingga tidak memenuhi syarat sebanyak 7 kapal [35\%] dan kapal yang tidak ditemukan tanda keberadaan tikus sehingga memenuhi syarat sebanyak 13 kapal [65\%]. Dari 7 kapal yang positif ditemukan tanda keberadaan tikus, ada 3 kapal yang tanda keberadaan tikusnya ditemukan di ruangan yang berbeda. Dan dari 10 tanda keberadaan tikus yang ditemukan, tanda yang paling banyak ditemukan yaitu ditemukannya kotoran tikus pada dapur kapal sebanyak 5 kali [50\%]. Berdasarkan hasil uji statistik, menggunakan uji alternatif yaitu uji Fisher Exact Test dan di peroleh nilai $p$ value $=0,017$ dengan demikian $\mathrm{p}$-value hitung < p-value $\alpha[0,05]$, berarti ada hubungan antara sanitasi kapal dengan tanda-tanda keberadaan tikus.

$$
\text { Bagi Kantor }
$$

KesehatanPelabuhanKelas II Banjarmasin Kantor Kesehatan Pelabuhan Kelas II Banjarmasin disarankan untuk lebih teliti dalam memonitor setiap ruangan kapal baik yang datang maupun berangkat serta mengoptimalkan pengawasan sanitasi kapal dan melaksanakan pemeriksaan keberadaan tikus dikapal sesuai dengan Peraturan Menteri Kesehatan Republik Indonesia Nomor 40 Tahun 2015 Tentang Sertifikat Sanitasi Kapal, Bagi Nakhoda dan ABK diharapkan selalu menjaga kebersihan kapal dan melakukan penyehatan kapal sesuai dengan saran dari petugas KKP, Bagi peneliti lain Perlu adanya kajian lebih lanjut terhadap sanitasi kapal dengan tanda-tanda keberadaan tikus dikapal dengan sampel kapal yang berbeda dari yang penulis teliti.

\section{UCAPAN TERIMA KASIH}

Penulis dalam kesempatan ini mengucapkan terima kasih atas segala bantuan dan dukungan kepada Bapak Yohanes Joko S, S.KM, M.Kes selaku dosen pembimbing utama dan Bapak Dr. H.M. Irfa'i S.ST. M.T selaku dosen pembimbing pendamping, dan Bapak Maharso, S.KM, $\mathrm{M}$,Kes, selaku dosen penguji dan kepada kedua orang tua yang memberikan dukungan moril dan materil serta semua pihak yang tidak bisa disebutkan satu persatu baik secara langsung maupun tidak langsung ikut membantu jalannya penyusunan skripsi ini.

\section{KEPUSTAKAAN}

1. Kementerian Pendidikan Nasional. 2010. Kamus Besar Bahasa Indonesia.

2. IHR. 2005. International Health Regulation. Jakarta. 
3. Permenkes RI. 2015. Peraturan Menteri Kesehatan Republik Indonesia No. 40 Tahun 2015, Sertifikat Sanitasi Kapal. Jakarta.

4. WHO. 2005. International Health Regulation, Alih Bahasa Kumara Rai. First Annoted Edition. Geneva.

5. Depkes RI. 2007. Surat Keputusan Menteri Kesehatan Nomor. 373/Menkes/SK/III/2007, Standar Profesi Sanitarian. Jakarta: Depkes RI.

6. Sembiring, F. Y. 2003. Hubungan Sanitasi Kapal dengan Keberadaan Tikus pada Kapal yang Berlabuh dipelabuhan Batu Ampar Batam. Universitas Sumatera.

7. Andriyani. 2005. Manajemen Sanitasi Pelabuhan Domestik. Jurnal Kesehatan Lingkungan, Vol 2. Hal 110.

8. KKP Kelas II Banjarmasin. 2015. Profil KKP Kelas II Banjarmasin. Arsip Tata Usaha KKP Kelas II, Banjarmasin.

9. Besral. 2010. Pengolahan dan Analisa Data 1. Departemen Biostatistika: Universitas Indonesia. 